\title{
Possibility of implementation of dry technology of gold-bearing ores roughing: case study of "Gurbey" deposit
}

\author{
Andrey Matveev ${ }^{1 *}$, Ivan Lebedev ${ }^{1}$, Evgeniy Lvov ${ }^{1}$, Diulustan Osipov ${ }^{1}$, Dmitry Gavriliev ${ }^{1}$ \\ and Ekaterina Sleptsova ${ }^{1}$ \\ ${ }^{1}$ Mining Institute of the North, Siberian Branch, Russian Academy of Sciences, Yakutsk, Russia
}

\begin{abstract}
The aim of the research is to identify the ability/feasibility of dry roughing of ore taking as the example "Gurbey" deposit in Irkutsk Region and to develop a rational scheme for processing ores containing free gold. Studies of the dry processing technology of gold-bearing ore at "Gurbey" deposit with the initial weight of $1,123.8 \mathrm{~kg}$ were carried out by semi-industrial plants: the DKD-300 combined shock impact crusher, the CMVU-800 centrifugal mill and the POS-2000 air separator developed by CNMI SD RAS. The sample was subjected to two cycles of crushing and four cycles of grinding followed by pneumatic separation. The circulating load is class $+12 \mathrm{~mm}$ after the DKD-300 crusher, and for the mill, all screening products are $+3 \mathrm{~mm}$, as well as the products of classification $-3+$ $1 \mathrm{~mm}$ of the POS-2000 concentrate. As a result of treatment of the concentration products, 23.93 grams of free gold was recovered (concentration on tables: control, recleaning, concentration of the Mosely minerals by analyzer, magnetic separation, heavy medium separation on bromoform). At the same time, it was established that gold from the ore with initial size of $150 \mathrm{~mm}$ can be completely stripped and recovered with the POS-2000 air separator with a particle size of up to 100 microns. At the same time gold extraction into the primary concentrate is up to $60 \%$. Based on the results of the research, a basic scheme for dry roughing of "Gurbey" ore containing "free" native gold was developed using the ore treatment devices: RD-MDV-900, DKD-300 crushers, CMVU-800 centrifugal mill and POS-2000 air separator. The technological scheme is fundamental for gold-bearing ores containing "free" gold of fineness over 100 microns. Keywords: Crushing, grinding, pneumoseparation, concentration, concentrate, magnetic enrichment, gold, stripping, recovery.
\end{abstract}

\section{Introduction}

CNMI SD RAS is developing a technology for dry enrichment of gold-bearing ores. For the ores of a number of fields, tests of semi-industrial plants have been carried out: the DKD300 combined shock impact crusher, the CMVU-800 centrifugal mill and the POS-2000 air separator. Tests have shown the prospects of implementing dry technology of preliminary

\footnotetext{
* Corresponding author: andrei.mati@yandex.ru
} 
ore dressing with free gold. For a number of deposits, it is possible to create a technological unit for preliminary reduction of the initial ore up to 400 times. At the same time, in most cases, the technology makes it possible to single out a separate enrichment product primary concentrate. The quantitative and qualitative parameters of this product depend on the fractional composition and nature of the dissemination of gold in the ore. In this paper, studies are done on the feasibility (efficiency) of dry roughing of ore at "Gurbey" deposit in Irkutsk Region, which is a definite stage in the development and implementation of dry technology for the enrichment of gold-bearing ores.

\section{Results and Discussion}

The aim of the research is to identify the feasibility of dry roughing of ore at "Gurbey" deposit in Irkutsk Region and to develop a rational scheme for processing ores containing free gold.

The choice of ore from "Gurbey" deposit, which contains a wide range of free-gold granulometry by its size and degree of impregnation, is of fundamental importance from the standpoint of investigating the depth of disclosure and extraction of gold.

The ore belongs to the gold-quartz-sulphide low-sulphide type of ores, mainly consisting of lithophilic components $(86.0 \%)$ with predominance of silicon oxide $(59.08 \%)$. The ore-forming components are mainly represented by iron and sulfur. The main rockforming minerals are quartz $(22.8 \%)$, chlorite $(21.7 \%)$ and feldspars $(20.7 \%)$. The sulphide part of the ore sample is represented by pyrrhotine $-2.3 \%$ and pyrite $-1.8 \%$. Gold, in general, is very high-grade, almost pure (938 - 964 units). The predominant mass of gold $(79.6 \%)$ is represented by classes of fineness $+0.071 \mathrm{~mm}$. The fraction of fine, thin and fine-dispersed particles of gold $(+0.071 \mathrm{~mm})$ is $20.4 \%$ [1].

Studies of the dry processing technology of gold-bearing ore at "Gurbey" deposit with initial weight of $1,123.8 \mathrm{~kg}$ were carried out using semi-industrial plants: the DKD-300 combined shock impact crusher [2], the CMVU-800 centrifugal mill [3] and the POS-2000 air separator [4] developed by CNMI SD RAS (Figure 1). The granulometric characteristics of the ore sample given after the primary crushing are presented in Table 1.

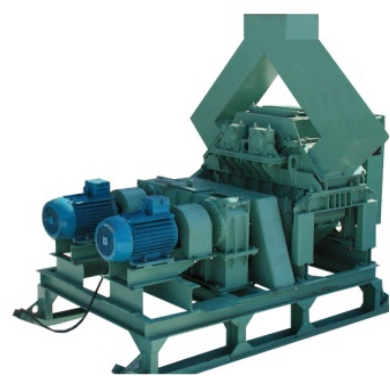

a

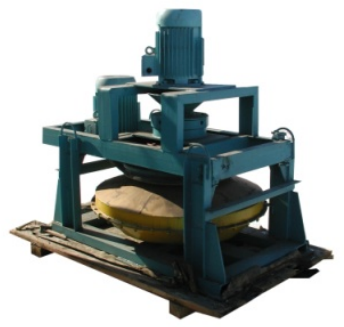

6

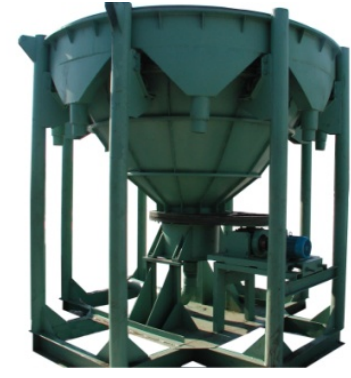

B

Fig. 1. $a$ - the DKD-300 combined shock impact crusher, $b$ - the CMVU-800 centrifugal mill, $c$ - the POS-2000 air separator

\subsection{Methodology of research}

In the initial ore contains about $20 \%$ of ore fines - a class of size $-1 \mathrm{~mm}$. With this in mind, screening was carried out for the original sample by the size classes $+12 \mathrm{~mm},-12+3 \mathrm{~mm}$ and $-3 \mathrm{~mm}$. The distribution of the original sample by size classes after classification was as 
follows: $+12 \mathrm{~mm}-673.4 \mathrm{~kg},-12+3 \mathrm{~mm}-197.1 \mathrm{~kg},-3 \mathrm{~mm}-253.3 \mathrm{~kg}$, total $1,123.8 \mathrm{~kg}$. The technological scheme of the studies is shown in Figure 2.

The grain size of $+12 \mathrm{~mm}$ was crushed by DKD-300, class $-12+3 \mathrm{~mm}$ by CMVU- 800 . The $-3 \mathrm{~mm}$ class was subjected to pneumoseparation by PIC-2000. It should be noted that the nominal size in the feed of the air separator is $-1 \mathrm{~mm}$. In this case, an enlarged version of the feed was adopted for maximum concentration into pneumoconcentrate of gold recovered from the ore mass, and also low efficiency of grinding by CMVU- 800 was taken into account due to deterioration of its parts.

Table 1. Granulometric composition of the initial sample

\begin{tabular}{|c|c|c|}
\hline \multirow{2}{*}{ Classes of size, $\mathrm{mm}$} & \multicolumn{2}{|c|}{ Yield } \\
\cline { 2 - 3 } & $\mathrm{kg}$ & $\%$ \\
\hline+100 & 173.51 & 15.44 \\
\hline$-100+40$ & 240.72 & 21.42 \\
\hline$-40+20$ & 181.61 & 16.16 \\
\hline$-20+10$ & 122.61 & 10.91 \\
\hline$-10+5$ & 57.20 & 5.09 \\
\hline$-5+2$ & 84.62 & 7.53 \\
\hline$-2+1$ & 45.06 & 4.00 \\
\hline$-1+0.0$ & 218.47 & 19.44 \\
\hline Total & $1,123.80$ & 100.00 \\
\hline
\end{tabular}

The concentrate obtained from the air separator was sieved into two classes +1 and -1 $\mathrm{mm}$. Then the class $-1 \mathrm{~mm}$ was enriched on the concentration table, then concentrate was made by "Henry Moseley" concentrator. For the final separation of free gold, magnetic separation and washing in bromoform were used.

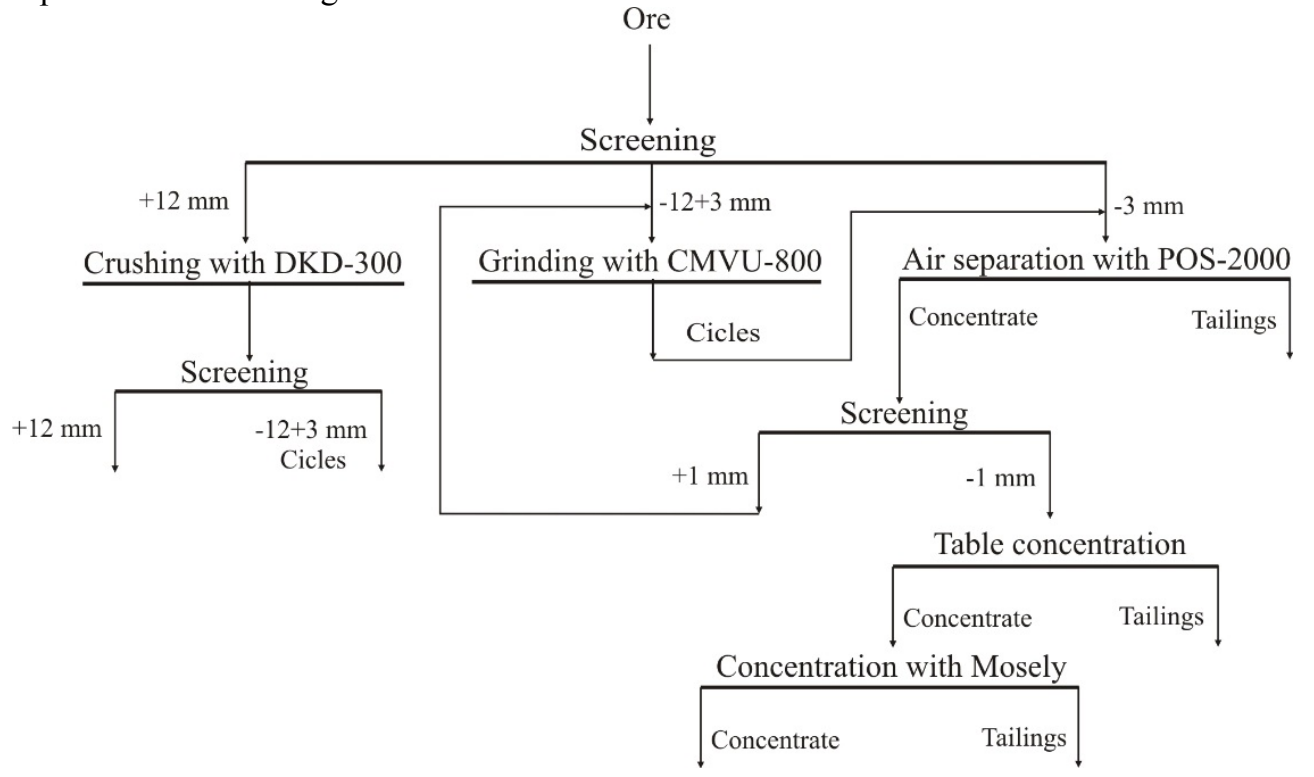

Fig. 2. Technological schemes of samples treatment 
The sample was subjected to cyclic crushing and grinding (4 cycles). Class $+12 \mathrm{~mm}$ after DKD-300 is recyclable for crushing (cycle), for the mill recyclable are all screening products $+3 \mathrm{~mm}$, as well as $-3+1 \mathrm{~mm}$ concentrates after POS-2000. At the same time, processing on CMVU-800 and POS-2000 was carried out strictly simultaneously. For each operation, samples for granulometric and assay analyzes for gold content (tailings of processing) were separately selected and processed.

At the final stage, a balance analysis of the processing products for gold content and calculation of recovery by processing cycles (crushing-grinding-pneumoseparation) was carried out.

The crushing was carried out according to the general technological scheme of processing samples with crushing of $+12 \mathrm{~mm}$ fractions, including recyclable classes after crushing (the basis for the formation of a circulating load in the technological scheme of crushing).

During the tests, it was found that for a given amount of the sample, two cycles of crushing are sufficient using DKD-300 (Table 2).

Table 2 shows that in the first cycle, the greatest degree of crushing is achieved with a value of 8.4. The second crushing cycle receives only two classes of size $-20+10 \mathrm{~mm}$ and $40+20 \mathrm{~mm}$ (the unbroken product after the first cycle is the basis of the circulation load), which is $19.85 \%$ and $10.78 \%$ of the total mass of the crushed product. As a result, the degree of crushing for the second cycle falls to 2.28, but the granulometric compositions of the products of crushing of the first and second cycles are quite close, which shows the efficiency of crushing by DKD-300.

Table 2. Granulometric composition of the products of crushing by DKD-300

\begin{tabular}{|c|c|c|c|}
\hline \multirow{2}{*}{$\begin{array}{c}\text { Classes of size, } \\
\mathrm{mm}\end{array}$} & \multicolumn{3}{|c|}{ Yield } \\
\cline { 2 - 4 } & Initial ore & Cycle 1 & Cycle 2 \\
\hline-0.063 & 5.98 & 2.93 & 2.25 \\
\hline$-0.1+0.063$ & 2.64 & 2.27 & 2.21 \\
\hline$-0.315+0.1$ & 5.76 & 7.35 & 6.03 \\
\hline$-0.5+0.315$ & 1.88 & 3.71 & 2.58 \\
\hline$-1+0.5$ & 3.19 & 7.46 & 5.46 \\
\hline$-2+1$ & 4.00 & 9.67 & 8.00 \\
\hline$-5+2$ & 7.53 & 20.73 & 20.46 \\
\hline$-10+5$ & 5.09 & 15.25 & 15.47 \\
\hline$-20+10$ & 10.91 & 19.85 & 29.6 \\
\hline$-40+20$ & 16.16 & 10.78 & 7.94 \\
\hline$-100+40$ & 21.42 & & \\
\hline+100 & 15.44 & & 2.28 \\
\hline Crushing degree & & 8.40 & \\
\hline
\end{tabular}

Grinding tests were carried out on CMVU-800 according to the general technological scheme of processing samples with grinding the fractions $-12+3 \mathrm{~mm}$. During the operation of CMVU-800, in the course of grinding process a fine-dispersed dusty mass of material with a size of $-0.063 \mathrm{~mm}$ is formed, up to $32 \%$ of the total amount of material to be crushed.

\subsection{Ore test results by cycles}

Initially, the screening products $-3 \mathrm{~mm}$ after screening of the original ore were tested $253,300 \mathrm{~g}(100 \%)$. After passing $-3 \mathrm{~mm}$ material in the air separator, $40 \%$ was recovered into the concentrate, while a high loss of mass occurs due to a spill in the feeding scheme of 
the air separator (conveyor) and in the tail section (fine-dispersed dusty mass). The spill should be attributed to the tailings, since additional blowing of the material by atmospheric wind occurs during transport to the air separator.

As a result of subsequent operations to extract gold from the concentrates, $9.22 \mathrm{~g}$ of gold was obtained.

A total of 2 cycles of crushing and 4 cycles of grinding followed by pneumoseparation were completed.

The samples were subjected to grinding and pneumoseparation, the losses in the mass in the form of spillage and fine-dispersed dust amounting to 32\%. From the POS-2000 concentrate, $5.74 \mathrm{~g}$ of gold were recovered.

Further, a large class of $+12 \mathrm{~mm}$ of the initial sieving of the original sample was treated. The distribution of the material after crushing by size classes is as follows: $+12 \mathrm{~mm}-$ $6.28 \%$, - 12+3 mm - 42.9\%; $-3 \mathrm{~mm}-29.8 \%$. Large classes of $+12 \mathrm{~mm},-12+3 \mathrm{~mm}$ form the basis for subsequent cyclic treatment. As a result of the treatment, the following were obtained: class $-1 \mathrm{~mm}-4.28 \mathrm{~g}$ from the products of sieving of the POS-2000 concentrate and class $+1 \mathrm{~mm}-1.32 \mathrm{~g}$ from the products of treatment of sieving of the POS-2000 concentrate. As a result, after processing of the initial sample, only $5.6 \mathrm{~g}$ was removed after the re-release by crushing of the large class chippings $+12 \mathrm{~mm}$.

Thus, the bulk of gold is in a free state in ore fines, and in the coarsely clastic part, gold is in a subordinate state, which indicates the selectivity of gold recovery at the stage of preliminary destruction.

\subsection{Tests of coarsely clastic part of the sample in cycles of crushing and grinding}

The initial feed of the crusher is class $+12 \mathrm{~mm}(100 \%)$. After the second crushing cycle, the residual quantity of the non-crushed material $+12 \mathrm{~mm}$ is only $6.28 \%$ or $42,300 \mathrm{~g}$. Further processing of these residues is impractical. The bulk of the ore passes into the classes $-12+3$ $\mathrm{mm}$ and is the feed for the mill, the grinding was performed in cycles (return to the grinding of the underground part). Moreover, for the subsequent cycles of grinding the feed of CMVU-800 is the product of sieving $+1 \mathrm{~mm}$ of POS-2000 concentrators (the mill and air separator work in gear). A total of four cycles of grinding-pneumoseparation were completed. The distribution of the products of grinding-pneumoseparation after grinding cycle 1 is as follows: concentrate $-20.08 \%$, tailings with blowing losses $-17.47 \%$, total losses - $22.82 \%$, i.e., concentrate yield from the operation of grinding-pneumoseparation is $46.8 \%$. After grinding cycle 2, the yield of the POS-2000 concentrate decreases to $6.32 \%$, the loss being $6 \%$, but the concentrate's operating yield is large $-51.21 \%$. After grinding cycle 3 , the yield of the concentrate is $2.79 \%$, the loss being $1.62 \%$, the operating yield of the concentrate is increased to $63.26 \%$. In cycle 4 , the concentrate yield is $1.27 \%$, the operating yield being $60.48 \%$. In general, there is a high level of the POS-2000 concentrates yield (more than half of the initial material is released to concentrate, this is due to undergrinding and relatively large-size feed of the air separator with $-3 \mathrm{~mm}$ class.) In the following, it is necessary to adjust the operating mode of the air separator, and apply another variant - treatment by the spiral air separator VPS-500, which has been tried, but the degree of reduction must be linked to the parameters of gold recovery.

\subsection{Granulometric characteristic of recovered gold}

As a result of treatment of the products of concentration, free gold was recovered by modifying (concentration on the tables: control, re-cleaning, concentration on Mosely minerals analyzer, magnetic separation, heavy separation with bromoform) - $23.93 \mathrm{~g}$ (Table 
3). Of these, $9.22 \mathrm{~g}$, or $38.56 \%$ of the total sample recovered during the processing, was recovered from the $-3 \mathrm{~mm}$ class of the preliminary sieving of the original sample, i.e., initially free gold in the original sample.

As the gold is released by crushing and grinding in cycles, the amount of free gold recovered decreases noticeably, which indicates a sufficient selective release, depending on the size and nature of the impregnation in the ore (the location of gold in the texture of the ore matrix).

In general, the release gives an additional recovery of $5.45 \mathrm{~g}$ of gold. But the recovery parameter is already lower and amounts to $77.56 \%$ with the POS-2000 concentrate yield of $45 \%$. The tailings of POS-2000 are characterized by a value already lower $-19 \mathrm{~g} / \mathrm{t}$, which is within the limits of reliable identification by the atomic-adsorption method. The high content of gold in the tailings of the concentration table and the "Henry Moseley" analyzer of 17.4 and $34.8 \mathrm{~g} / \mathrm{t}$ shows approximately equal but low level of enrichment, dry separation, and wet methods of gravitational separation. A possible cause is the thin impregnation of gold in the ore, which has yet to be studied and evaluated technologically.

Table 3. Volume of recovered uncleaned gold

\begin{tabular}{|l|c|c|}
\hline \multirow{2}{*}{ Treatment products } & \multicolumn{2}{c|}{ Yield } \\
\cline { 2 - 3 } & $\mathrm{g}$ & $\%$ \\
\hline Pneumoseparation without crushing and grinding $-3+1 \mathrm{~mm}$ & 9.22 & 38.56 \\
\hline Product of original sample after grinding $-12+3 \mathrm{~mm}$ & 5.74 & 24.01 \\
\hline Products of crushing -3 mm cycle 1 & 4.28 & 17.90 \\
\hline Products of crushing -3+1 mm cycle 1 & 1.32 & 5.52 \\
\hline Products of grinding -12+ 3 mm cycle 1 & 2.56 & 10.71 \\
\hline Products of grinding -3+1 mm cycle 2 & 0.51 & 2.13 \\
\hline Products of grinding -3+1 mm cycle 3 & 0.25 & 1.05 \\
\hline Products of grinding -3+1 mm cycle 4 & 0.05 & 0.13 \\
\hline Total & 23.93 & 100.00 \\
\hline
\end{tabular}

Figure 3 presents the proposed schematic diagram of dry ore enrichment with a controlled parameter of the degree of crushing and grinding, due to the formation of circulating flows through a classifying device (screen).

It was experimentally established that when circulating loads on DKD-300 in the +12 $\mathrm{mm}$ class, the yield is $12.36 \%$ and on CMVU- 800 in the $+1 \mathrm{~mm}$ class is $84.41 \%$, which is ultimately characterized by the total yield of the control class of $0.063 \mathrm{~mm}$ in size within $35 \%$ which allows to completely release and recover with POS-2000 the gold of size up to 100 microns. In this case, gold recovery into the primary concentrate is up to $60 \%$, which corresponds to the initial granulometric composition of gold in the ore, which is confirmed by the enrichment of the products of pneumatic separation with POS-2000 by "wet" gravitational enrichment methods (concentration table, "Henry Moseley" analyzer with recovery and release of free gold). Tailings of dry enrichment are subject to subsequent enrichment using various methods, including flotation or cyanidation.

\section{Conclusions}

A basic scheme for dry roughing of ores containing "free" native gold has been developed using the ore treatment devices: RD-MDV-900, DKD-300 crushers, centrifugal mill CMVU-800 and air separator POS-2000 with full release and recovery of gold with a size of up to 100 microns into the primary concentrate. 
For the developed principle scheme of dry roughing of gold-bearing ores, the limiting condition is the possibility of full release and recovery of gold of a size above 100 microns, according to which all other technological parameters are calculated, first of all recovery, degree of concentration, gold content in tailings, necessary for subsequent enrichment operations.

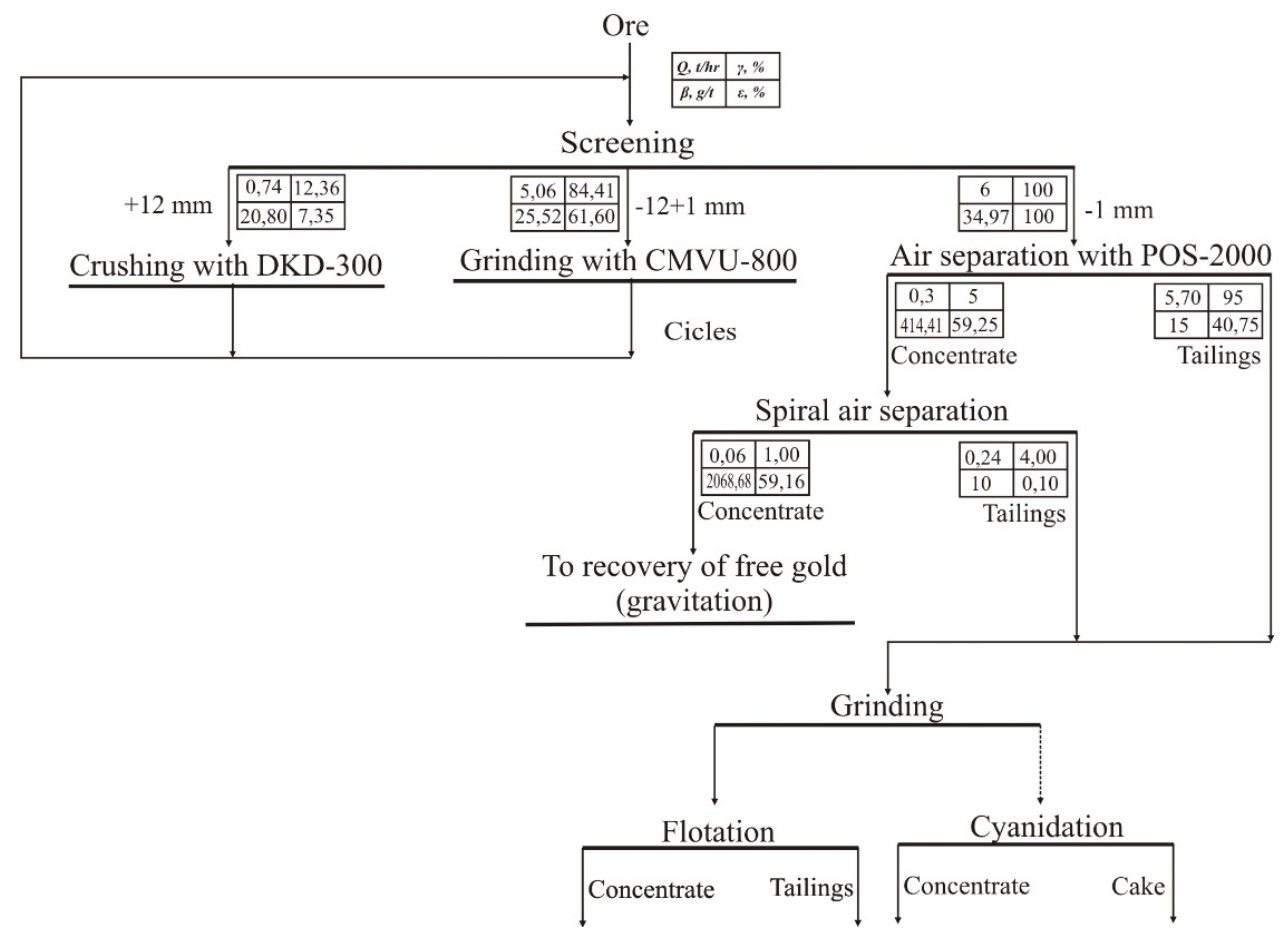

Fig. 3. Schematic diagram of dry roughing of gold-bearing ores: case study of "Gurbey" deposit

\section{References}

1. OAO Irgiredmet report on the research work "Conducting research on the technological properties of the TP-1 sample at "Gurbey" deposit" (Final), Irkutsk city, (2017)

2. Patent of the Russian Federation No.2111055. A.I. Matveev, V.P. Vinokurov, A.N. Grigorev, A.M. Monastyrev, CNMI SD RAS of May 20, 1998. Crusher of combined impact action. BI No.14.

3. Patent No.2150323 7 B 02 C 13/20. Centrifugal counter-blow mill / A.I. Matveev, A.N. Grigorev, V.E. Filippov / CNMI SD RAS. Submitted on October 28, 1997; published on June 10, 2000 // Inventions. Useful models. 16. Part 2. p. 268. (2000)

4. Patent No.2167005, 7 B 07 B 7/08. Air separator / A.I. Matveev, V.E. Filippov, F.M. Fedorov, A.N. Grigorev, V.B. Iakovlev, N.G. Eremeeva, E.S. Sleptsova, A.M. Gladyshev, V.P. Vinokurov / CNMI SD RAS. Submitted on June 11, 1999; published on May 20, 2001. // Inventions. Useful models. 14. Part 2. p. 346. (2001) 